\title{
Attitudes without Monsters: A Japanese Perspective
}

\author{
Toshiyuki Ogihara \\ University of Washington
}

\section{Introduction}

The semantics of attitude verbs (believe, deny, etc.) and indirect discourse verbs (say, state, etc.) has long been an important topic for philosophy of language and natural language semantics. The point made by Frege (1892) remains valid to this day, which is that an attitude verb creates an intensional context in that the semantic contribution made by its sentential complement cannot be its denotation (i.e., a truth value). Nevertheless, It is not easy to pinpoint precisely the semantic contribution of the complement clause. Let us first consider several different ways of formalizing the semantics of attitude verbs. The truth conditions for (1) could be formalized in various ways as shown in (2a-d). Throughout this paper, $w_{0}$ and $t_{0}$ represent the actual world and the utterance time, respectively.

(1) John believes that Mary is pregnant.

(2) a. Hintikka (1969): (1) is true in $w_{0}$ iff $\{\mathrm{w} \mid \mathrm{w}$ is not precluded by John's belief in $\left.\mathrm{w}_{0}\right\} \subseteq\{\mathrm{w} \mid$ Mary is pregnant in $\mathrm{w}\}$

b. Hintikka (1969) with an ontology containing times: (1) is true at $t_{0}$ in $\mathrm{w}_{0}$ iff $\left\{\mathrm{w} \mid \mathrm{w}\right.$ is not precluded by what John believes at $\mathrm{t}_{0}$ in $\left.\mathrm{w}_{0}\right\} \subseteq\{\mathrm{w}$ | Mary is pregnant at $t_{0}$ in $w$ \}

c. Montague (1973): (1) is true at $\mathrm{t}_{0}$ in $\mathrm{w}_{0}$ iff $\{<\mathrm{w}, \mathrm{t}\rangle|<\mathrm{w}, \mathrm{t}\rangle$ is not precluded by what John's belief at $\mathrm{t}_{0}$ in $\left.\mathrm{w}_{0}\right\} \subseteq\{<\mathrm{w}, \mathrm{t}\rangle \mid$ Mary is pregnant at $\mathrm{t}$ in $\mathrm{w}\}$

d. Lewis (1979): (1) is true at $\mathrm{t}_{0}$ in $\mathrm{w}_{0}$ iff $\{<\mathrm{x}, \mathrm{w}, \mathrm{t}\rangle \mid<\mathrm{x}, \mathrm{w}, \mathrm{t}>$ is a doxastic alternative of John at $\mathrm{t}_{0}$ in $\left.\mathrm{w}_{0}\right\} \subseteq\{<\mathrm{x}, \mathrm{w}, \mathrm{t}>\mid$ Mary is pregnant at $\mathrm{t}$ in w\}

If we assume that a proposition is a set of worlds and ignore times completely, then the truth conditions for (1) would be analyzed as in (2a) à la Hintikka (1969). Put informally, a sentence of the form " $\alpha$ believes $p$ " is true iff every world that is not precluded by what $\alpha$ believes is where $p$ is true (i.e., is an element of the intension of $p$ ). In this characterization, a proposition is (the characteristic

I thank the audience of SALT 16 for valuable comments and suggestions, in particular Makoto Kanazawa, Uli Sauerland, James Higginbotham, Sophia Malamud, David Oshima, Katsuhiko Yabushita, and Yasunari Harada. Needless to say, all errors and inadequacies are mine. 
function of) the set of worlds in which the sentence in question is true. If we introduce times and still subscribe to the view that a proposition is a set of worlds, then we obtain the truth conditions given in (2b), where the time of Mary's being pregnant is specified as $t_{0}$.

Montague (1973) reinterprets the concept of proposition as (the characteristic function of) a set of world-time pairs rather than as (the characteristic function of) a set of worlds. This translates into a different semantic analysis of attitude verbs. In Montague's account, an attitude verb denotes a relation between individuals and sets of world-time pairs. More specifically, (1) is true iff every world-time pair not precluded by $\alpha$ 's belief at the utterance time in the actual world is where $p$ is true. Put another way, $\{<\mathrm{w}, \mathrm{t}\rangle \mid<\mathrm{w}, \mathrm{t}>$ not precluded by $\alpha$ 's belief at the utterance time in the real world $\}$ is required to be a subset of $\{<w, t>\mid p$ is true at $t$ in $w\}$ as shown in (2c). Regarding (1) we can say that every world-time pair not precluded by what John believes at the utterance time in the actual world is a world-time pair at which Mary is pregnant. This approach is arguably more flexible than Hintikka's approach, and this point will be elaborated below.

Lastly, (2d) describes Lewis's (1979) analysis of attitude verbs. This analysis essentially treats an attitude verb as involving a relation between individuals and properties, where properties are sets of individual-world-time triples. Accordingly the truth conditions for (1) are given as in (2d). As far as (1) is concerned, introducing a property rather than a proposition in (2d) seems superfluous because no individual variable is bound in specifying the property here. However, when we turn to more complex examples, the strength of Lewis's proposal becomes apparent. Consider Perry's (1977) well-known example in (3a) regarding this issue.

(3) a. Heimson believes that he is Hume.

b. Heimson believes that he is Napoleon.

Heimson, who is insane, believes himself to be Hume. On the other hand, Heimson, though he may be insane, does not believe that he is Napoleon. Given this scenario, (3a) is true but (3b) is false. This would be a problem if believe denotes a relation between individuals and propositions (regardless of whether a proposition is a function from worlds into truth values or a function from worldtime pairs into truth values). (3a) and (3b) share the same subject (i.e., Heimson), and both Heimson is Hume and Heimson is Napoleon are necessary false propositions equivalent to the empty set. One therefore would have to conclude that (3a) and (3b) are truth-conditionally equivalent. This is an undesirable prediction.

Lewis's (1979) account, which involves relations between individuals and properties, provides a solution to this problem. According to this approach the truth conditions for (3a) are given as in (4a), whereas the truth conditions for (3b) 
are specified as in $(4 b)$.

a. (3a) is true at $\mathrm{t}_{0}$ in $\mathrm{w}_{0}$ iff $\{<\mathrm{x}, \mathrm{w}, \mathrm{t}\rangle|<\mathrm{x}, \mathrm{w}, \mathrm{t}\rangle$ is a doxastic alternative of Heimson at $\mathrm{t}_{0}$ in $\left.\mathrm{w}_{0}\right\} \subseteq\{<\mathrm{x}, \mathrm{w}, \mathrm{t}\rangle \mid \mathrm{x}$ is Hume at $\mathrm{t}$ in $\left.\mathrm{w}\right\}$

b. (3b) is true at $t_{0}$ in $w_{0}$ iff $\{<x, w, t>\mid<x, w, t>$ is a doxastic alternative of Heimson at $\mathrm{t}_{0}$ in $\left.\mathrm{w}_{0}\right\} \subseteq\{<\mathrm{x}, \mathrm{w}, \mathrm{t}>\mid \mathrm{x}$ is Napoleon at $\mathrm{t}$ in $\mathrm{w}\}$

Intuitively, Lewis' account enables us to talk about attitudes as self-ascription of properties. Such beliefs are referred to as de se beliefs after Lewis and the pronoun he in (3a) or (3b) is often referred to as a de se pronoun.

Under Lewis's analysis, (3a) is now understood to mean that Heimson self-ascribes the property $\{<\mathrm{w}, \mathrm{t}, \mathrm{x}>\mid \mathrm{x}$ is Hume at $\mathrm{t}$ in $\mathrm{w}\}$. That is, the pronoun he is understood to be a bound variable. Since the property $\{<\mathrm{w}, \mathrm{t}, \mathrm{x}>\mid \mathrm{x}$ is Hume at $\mathrm{t}$ in $\mathrm{w}\}$ is distinct from the property $\{<\mathrm{w}, \mathrm{t}, \mathrm{x}\rangle \mid \mathrm{x}$ is Napoleon at $\mathrm{t}$ in $\mathrm{w}\}$, Lewis's analysis enables (3a) and (3b) to have different truth values. This is empirically correct. However, it is not clear how to derive a property (rather than a proposition) from the complement clause he is Hume in (3a). In other words, the question is how to force the pronoun he to be bound by a binder in a compositional manner.

Schlenker $(1999,2003)$ proposes a system in which attitude verbs are semantically analyzed in a way substantially different from the aforementioned approaches. He contends that an attitude verb is a "monster" in the sense of Kaplan (1977/1989). Kaplan (1977/1989) proposes a system for semantics which involves three levels: character, content (intension), and extension. This system enables Kaplan to account for the characteristics of so-called indexical expressions such as I, you, now, here, etc. whose denotations are fixed in relation to the utterance context. According to Kaplan's proposal, indexical expressions have contents that are context-dependent. Non-indexicals are in turn defined as those expressions whose extensions depend upon evaluation worlds/times. This proposal about natural language semantics enables us to distinguish between expressions whose meanings depend upon contexts (i.e. indexicals) and those with meanings that depend upon worlds (or world-time pairs). More concretely, indexicals such as $I$ and you have constant characters but variable contents (depending upon the context). Kaplan denies the existence of monsters, which are operators that manipulate contexts. Schlenker $(1999,2003)$ disagrees with Kaplan and argues that attitude verbs are "monsters" in that they denote relations between individuals and contexts. This is technically and conceptually distinct from the more traditional views about attitudes presented in (2).

Schlenker's idea that attitude verbs are monsters stems from the fact that in some languages indexicals can occur in verb complement clauses and produce interpretations which indicate what we might call "relative interpretations". What is a "relative interpretation" of an indexical? An indexical is used under normal circumstances to refer to an object definable only in relation to the utterance 
context. For example, in English $I$ refers to the speaker of the utterance context; now refers to the time of the utterance context. We might refer to these standard uses of indexicals as "absolute interpretations". Schlenker observes that in some languages (including Amharic) indexicals are interpreted in verb complement clauses in relation to the context of the reported attitude, not in relation to the utterance context. I will use the term "relative interpretation" to refer to this usage of indexicals because it is similar to the way in which the Japanese present tense (understood to be a relative tense (Ogihara 1996)) is used in verb complement clauses.

In Amharic, the first person pronoun 'I' can occur in the embedded clause to indicate the speaker of the attitude context. This is shown in (5a). The first person pronoun 'I' occurs in (5a) to indicate the agent of the reported speech act, namely John. Schlenker denies the possibility that the embedded clause is a quoted sentence by citing examples like (5b), where the embedded clause has both the subject 'I' and the object 'me'. If it were a direct quote, it would mean that 'he' will not obey 'himself', but it actually means that 'he' will not obey 'me' (the speaker of the entire sentence). Thus, the clause cannot be a direct quote. Schlenker represents the semantics of attitude verbs as in (6). The basic idea is clear here. An attitude verb is analyzed as a quantifier over a set of contexts: those contexts that could be the context of the attitude.

a. john Jgna naNN yt-lall

John hero I-am says-3rd sg.m

'John says that he is a hero.'

b. aldttazzäzäNN alä.

I-will-not-obey-me he-said

'He said that he will not obey me.' (or 'He refused to obey me.')

(6) Schlenker's semantics of attitude verbs: A sentence of the form "John believes $S$ " uttered at $t_{0}$ in $w_{0}$ is true iff $\{c \mid c$ (context) is compatible with what John believes at $\mathrm{t}_{0}$ in $\left.\mathrm{w}_{0}\right\} \subseteq\{\mathrm{c} \mid$ ' $\mathrm{I}$ am a hero' is true in $\mathrm{c}\}$ (paraphrasing Schlenker 2003: 73)

In the rest of this paper, I will present some problems with Schlenker's approach, and propose an alternative that is empirically and conceptually more desirable. In essence, my proposal defends Lewis's proposal for the relevant data drawn from Japanese and Amharic. To the extent that my proposal is couched in Lewis's property-based approach to the semantics attitudes, it is very similar to von Stechow's (2003). The main difference is that I account for the occurrences of "relative indexicals" by assimilating them to relative tenses in Japanese, whereas von Stechow attempts to explain their behavior in terms of feature checking and deletion mechanisms. 


\section{Problems with the Monster-based Approach}

As mentioned in Section 1, Schlenker's claim about attitude verbs is that they are monsters in the sense of Kaplan and are quantifiers over contexts. I argue with von Stechow (2003) that even though the data that Schlenker discusses are important for the semantics of attitude verbs, this conclusion is not warranted. Like von Stechow (2003), I contend that Lewis's analysis of attitudes in terms of relations between individuals and properties successfully accounts for the behavior of quasi-indexicals (Schlenker's terminology) in verb complement clauses. By assuming that the object of an attitude is a property, the information about the attitude context can be transmitted indirectly via the bound individual variable since the property is self-ascribed to the attitude holder, who is in the center of the reported context. For example, (7a) (=5a) would be understood to have the truth conditions given in (7b), where the first person pronoun ' $I$ ' corresponds to the bound individual variable $\mathrm{x}$. This is sufficient to show that the embedded ' $\mathrm{I}$ ' is understood to be the holder of the attitude being reported, namely John.

a. john Jgna naNN yt-lall

John hero I-am says-3rd sg.m

'John says that he is a hero.'

b. $\left\{<\mathrm{x}, \mathrm{w}, \mathrm{t}>\mid<\mathrm{x}, \mathrm{w}, \mathrm{t}>\right.$ is a doxastic alternative of John at $\mathrm{t}_{0}$ in $\left.\mathrm{w}_{0}\right\} \subseteq$ $\{<\mathrm{x}, \mathrm{w}, \mathrm{t}\rangle \mid \mathrm{x}$ is a hero at $\mathrm{t}$ in $\mathrm{w}\}$

Informally:

John talks at $t_{0}$ in $w_{0}$ as if he self-ascribes the following property: $\{<\mathrm{x}, \mathrm{w}, \mathrm{t}>\mid \mathrm{x}$ is a hero at $\mathrm{t}$ in $\mathrm{w}\}$

The main difference between my proposal and von Stechow's resides in how the lexical semantics of the Amharic ' $\mathrm{I}$ ' is given. I assume that the Amharic ' $\mathrm{I}$ ' is an individual variable that is necessarily bound by the individual variable binder and is not exactly a first person indexical. Von Stechow, on the other hand, assumes that the Amharic ' $I$ ' is a regular first person indexical pronoun. When it occurs in a verb complement clause, its feature is deleted and it is interpreted as a bound variable.

Schlenker's proposal also suffers from a conceptual problem, which may develop into a technical problem as well. Under Schlenker's analysis, it seems natural to assume that all indexicals (including 'here', 'you', 'yesterday', 'tomorrow', 'now', etc.) that occur in complement clauses receive "relative" interpretations. This is not attested in the world's languages. There does not seem to be a language where all occurrences of all indexicals receive relative interpretations. In fact, Schlenker openly acknowledges that some sentences in Amharic are multiply ambiguous because the indexical expressions can be interpreted either in relation to the utterance context (absolutely) or the reported 
attitude context (relatively). Here is one example cited by Schlenker (1999: 36).

mon $\partial$ wädalläxw ${ }^{w}$ ndaläalsämac $\partial \mathrm{m}$ what I-like that-he-said she-didn't-hear

'She didn't hear what he said he liked' or 'She didn't hear what he said I liked'

In one of the examples Schlenker cites (i.e. $5 b$ repeated here as 9), the first person pronoun occurs twice, as the subject ' $\mathrm{I}$ ' and as the object 'me'. This example is used by Schlenker to show that the complement clause is not a direct quote. His point is clear. However, this example also reveals a problem with his approach because it is not clear why it is possible for the two occurrences of the pronoun 'I' in (9) to be interpreted in two different ways: one in relation to the embedded context, the other in relation to the utterance context. This shows that only some occurrences of some indexicals are interpreted in relation to embedded contexts and casts doubt upon the predictive ability of the system Schlenker proposes.

alðttazzäzäNN alä.

I-will-not-obey-me he-said

'He said that he will not obey me.' (or 'He refused to obey me.')

Schlenker says that as long as some indexicals receive relative interpretations, we need a monster-based approach. But as shown above, Lewis's property-based approach gives us all the machinery we need to account for the behavior of such indexicals.

Regarding tense, Schlenker's proposal accounts for the fact that in languages like Russian the simple present tense behaves like a relative tense in verb complement clauses but not in relative clauses. (10a) shows that the Russian present behaves like a relative past in a verb complement clause. On the other hand, (10b) involves a relative clause and shows that a present tense can only be interpreted absolutely (i.e., in relation to the utterance time) (Schlenker 2003: 70).

a. petjai skazal, čto on plačet

Pejta $a_{i}$ said that he is-crying

'Petja said that he was crying [at the time of his utterance].'

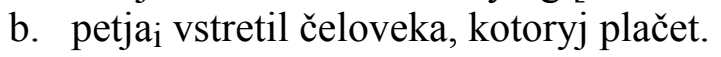

Petja met a person who is crying/cries.'

Schlenker's proposal explains the difference between (10a) and (10b) in terms of the presence of quantification over contexts (or lack thereof). The present tense morpheme in (10a) is capable of receiving a relative interpretation because the attitude verb forces us to consider times that are associated with the reported attitude (i.e., 'say'). Since the context is not shifted by an operator in (10b), the 
present tense morpheme is interpreted in relation to the utterance time.

Unfortunately, as shown in Ogihara (1996), Japanese tense morphemes can receive relative interpretations in both verb complements and relative clauses, except that in relative clauses tenses have the option of receiving absolute interpretations. Consider the examples $(11 \mathrm{a}, \mathrm{b})$.
a. Taroo-wa [Hanako-ga byooki-da] to omot-te $\mathrm{i}$-ta.
Taro-TOP Hanako-NOM sick-be-PRES that think-PROG-PAST
'Taro thinks that Hanako was sick (at that time).'
b. Taroo-wa [nanika sakende-iru] otoko-ni at-ta.
Taro-TOP [something(-acc) shout-PROG-PRES man-to see-PAST
'Taro saw a man who was shouting something (at the time of seeing him)' or
'Taro saw a man who is now shouting something'

For Schlenker, the reason that a sentence in the present tense can be interpreted in relation to the time of the matrix verb rather than in relation to the utterance time is that an attitude verb is a quantifier over contexts (i.e., a monster). However, in Japanese, tenses in relative clauses as well as verb complement clauses can be interpreted in relation to the matrix verb. This is shown in $(11 \mathrm{a}, \mathrm{b})$. Ogihara (1996) contends that a Japanese sentence "in the present tense" is actually a tenseless sentence, and that this assumption allows us to account for data like $(11 \mathrm{a}, \mathrm{b}) .{ }^{1}$ It seems then that to explain relative interpretations of indexicals in terms of quantification over contexts is a questionable move according to the Japanese data.

\section{Attitudes and Agreement Phenomena}

Von Stechow (2003) argues for the view that some pronouns are subject to a "sequence-of-persons" rule, in that they can lose their (person, gender, number) features when some conditions are satisfied. The idea is to deal with the case of pronouns in a way analogous to the case of tenses. Just as it is natural to propose a sequence-of-tense rule to account for the English data, it is natural to employ a "sequence-of-persons rule" to account for some relevant data in the nominal domain. The major idea is that when one nominal locally c-commands a pronoun and they agree in person, number and gender, then the latter loses these features

\footnotetext{
${ }^{1}$ Technically, a tenseless sentence is encoded as a set of world-time pairs $<\mathrm{w}, \mathrm{t}>$ such that the conditions specified by the sentence hold at $t$ in w. To my knowledge, Stump (1985) was the first to posit the level of a tenseless sentence and to translate it into a temporal abstract (a set of times at which the conditions specified by the sentence obtain). This was needed to account for the behavior of tenses and temporal adverbials in English.
} 
and become "plain variables". This is true of normal bound variable cases like (12a), and that is also true of an exceptional case like (12b) (cited by Kratzer 1998, who attributes it to Irene Heim).

(12) a. [Every boy $]_{1}$ thinks that he ${ }_{1}$ is the smartest.

b. [Only $\mathrm{I}_{1}$ got the question that $\mathrm{I}_{1}$ understood.

The idea is that pronouns often behave like "pure" variables and this is explained in terms of feature deletion. In cases like (12a, b), feature deletion occurs under identity, a concept very similar to tense (feature) deletion for the sequence-of-tense phenomena. This strategy is adopted by Kratzer (1998) and von Stechow (2003). This works very well to explain the behavior of so-called de se pronouns in English and some related languages (such as German). However, as far as "relative indexicals" such as ' $I$ ' in Amharic are concerned, this strategy necessitates an ad hoc rule such as the one in (13) adopted by von Stechow (2003) (attributed to Irene Heim 2001).

(13) The first person parameter:

Amharic verbal quantifiers delete the feature 1st of the person variable they bind, regardless of what their person checkee is.

In my own proposal, I contend that alleged indexicals which receive relative interpretations in verb complement clauses are not indexicals but are pronouns with designated indices that must be bound. Intuitively, this means that the Amharic ' $\mathrm{I}$ ' is parallel to the Japanese present in that it has no inherent utterancecontext orientation.

\section{Felicity Conditions for Utterances}

As a first step toward a full-fledged proposal for attitudes, I adopt a truth conditional theory for natural language that incorporates speech act theory. Austin (1962) contends that an utterance of a sentence constitutes a speech act, and it is reasonable to assume that the very basic illocutionary speech act associated with an utterance of a natural language sentence is that of asserting or claiming. We can go one step further and assume with Grice (1975) that the speaker must have good reason to assert the content of the sentence. Thus, when someone utters a sentence in a way that satisfies Grice's maxim of quality, we should regard this utterance event as a self-ascription of a relevant property by the speaker. Ogihara (1996: 62, 250) expresses this view in terms of a truth definition and accounts for the behavior of relative tense morphemes in Japanese. In this paper, I extend this approach to those indexical pronouns that receive relative interpretations. We then apply this approach to attitude reports. 
The proposal defended here analyzes (14a) as in (14b). Taro's speech act of uttering the sentence in question is reanalyzed as an illocutionary act of asserting and believing. This is then encoded in terms of self-ascription of a property by Taro.

a. Taro: Hanako-wa byooki-da.

Hanako-TOP sick-be-PRES 'Hanako is sick.'

b. Taro self-ascribes at the utterance time in the actual world the following property: $\{<\mathrm{x}, \mathrm{w}, \mathrm{t}>\mid$ Hanako is sick at $\mathrm{t}\}$

We shall see below that this approach accounts for the relative interpretations of some alleged indexical pronouns.

In order to obtain the semantics in (14b) in a compositional way, I propose the semantic rule in (15). I pretend here that we are dealing with an idealized relative indexical language that has a relative tense system (on a par with Japanese) and a relative indexical pronoun for the first person (on a par with Amharic). Since the language is exactly like Japanese regarding tense, there is no "relative present indicator" as such and the sentence itself is interpreted as a function of type $<\mathrm{s},<\mathrm{i}, \mathrm{t}>>$ ( $s$ for worlds, $i$ for time intervals, and $t$ for truth values). ${ }^{2}$

(15) Assumptions: A first person quasi-indexical (e.g., the Amharic 'I') bears the designated index $<0, \mathrm{e}>$, which indicates the zeroth index of type e, When the speaker $\alpha$ utters a sentence $S$ at $t_{0}$ in $w_{0}$, the speech act is appropriate iff $\{<\mathrm{x}, \mathrm{w}, \mathrm{t}\rangle \mid<\mathrm{x}, \mathrm{w}, \mathrm{t}>$ is a doxastic alternative of $\alpha$ at $\mathrm{t}_{0}$ in $\left.\mathrm{w}_{0}\right\}$ $\subseteq\left\{<\mathrm{x}, \mathrm{w}, \mathrm{t}>\mid \llbracket \mathrm{S} \rrbracket_{\mathrm{c}}^{\mathrm{g}} \mathrm{x} /<0, \mathrm{e}>(\mathrm{w})(\mathrm{t})=1\right\}$

(Note that $\mathrm{g}_{\mathrm{c}} \mathrm{x} /<0$,e $>$ indicates that function exactly $\mathrm{g}_{\mathrm{c}}$ (assignment furnished by context $\mathrm{c}$ ) except that it assigns $\mathrm{x}$ to $<0$, e $>$. See Heim and Kratzer (1998) for the notation as well as the necessary background information.)

This proposal assumes that the "indexical" I is simply a pronoun that must have a special index that is mapped to a variable bound by the individual variable binder. Thus, the Amharic ' $I$ ' is not an indexical in the strict sense in my proposal. If the sentence has a second person pronoun you that behaves like a quasi-indexical, then it would be mapped to the person that is related to $\mathrm{x}$ via an acquaintance relation (Cresswell and von Stechow 1982). But this discussion would take us too far afield. So I will only discuss the case of the first person here.

\footnotetext{
${ }^{2}$ If there is a language that has an overt present tense morpheme that arguably indicates the position of "relative present", then we could let the present tense morpheme bear the designated index $<0, \mathrm{i}>$ on a par with the Amharic ' $\mathrm{I}$ '.
} 
So far, I have discussed those cases in which the object language expression in question has the form of a sentence. But given that a natural language utterance involves a self-ascription of a property by the speaker, we should pay attention to the fact that many natural language utterances constitute incomplete sentences. At least in Japanese, this is almost always the case. The idea that I shall pursue here is that an utterance of a property denoting expression (e.g., an intransitive verb without a subject nominal) is a norm rather than an exception. Faced with an example like (16a), the felicity condition for an utterance given above as (15) is slightly changed as in (16b). Consequently, (16a) receives the interpretation given in (16c).
a. Taroo-ni at-teiru yo.
Taro-dat meet-PROG-PRES YO
'(I) am meeting Taro.'

b. When the speaker $\alpha$ utters a predicate $P$ at $t_{0}$ in $w_{0}$, the speech act is appropriate iff $\left\{<\mathrm{x}, \mathrm{w}, \mathrm{t}>\mid<\mathrm{x}, \mathrm{w}, \mathrm{t}>\right.$ is a doxastic alternative of $\alpha$ at $\mathrm{t}_{0}$ in $\left.\mathrm{w}_{0}\right\} \subseteq\left\{<\mathrm{x}, \mathrm{w}, \mathrm{t}>\mid \llbracket \mathrm{P} \rrbracket \mathrm{g}_{\mathrm{c}}(\mathrm{x})(\mathrm{w})(\mathrm{t})=1\right\}$ (P is assumed to a function in $\mathrm{D}_{<\mathrm{e},\langle\mathrm{s},\langle\mathrm{t}\rangle>>}$ )

c. An utterance of (16a) by $\alpha$ at $\mathrm{t}_{0}$ in $\mathrm{w}_{0}$ is felicitous iff $\alpha$ self-ascribes the following property at $t_{0}$ in $w_{0}:\{<x, w, t>\mid x$ is meeting Taro at $t$ in w\}

This straightforwardly captures the idea that uttering a sentence means selfascribing a property denoted by the expression uttered by the speaker. (17a) is a similar example, and (17b) provides the felicity condition for its utterance.

a. Soto-ni iru yo. outside-at be-pres YO '(I) am outside.'

b. The speaker self-ascribes the following property at $t_{0}$ in $w_{0}:\{<x, w, t>$ $\mid \mathrm{x}$ is outside at $\mathrm{t}$ in $\mathrm{w}\}$

Thus, "incomplete sentences" in Japanese are in fact desired linguistic objects for semantic interpretation in this proposal.

Needless to say, the entity that corresponds to a missing nominal position does not always correspond to the speaker. For example, in (18a) the empty category in Taro's utterance indicates Jiro, rather than the speaker (i.e., Taro). In this case, the missing subject must be an empty referential pronoun and the context must furnish an appropriate individual as its referent as shown in (18b).

\footnotetext{
${ }^{3}$ The particle yo indicates (among other things) the speaker's belief that the information conveyed by the sentence is important to the hearer. This is not absolutely necessary but makes the utterance natural.
} 
(18)

a. Hanako: Jiroo-wa ki-ta?

Jiro-top come-past

'Did Jiro come?'

Taro: Un, ki-ta yo. yes, (he) came.

'Yes, he did.'

b. Taro's utterance at $t_{0}$ in $w_{0}$ is felicitous iff Taro self-ascribes at $t_{0}$ in $\mathrm{w}_{0}$ the following property: $\{<\mathrm{x}, \mathrm{w}, \mathrm{t}>\mid$ Joro comes at some time earlier than $\mathrm{t}$ in $\mathrm{w}$ \}

Thus, the empirical coverage of (16b) is limited. But it is nevertheless appealing to think of (16b) as the default rule for a hearer to use when she hears a "predicate". 4

\section{Proposal}

The proposal defended in this paper extends the idea of tenseless sentences to the nominal domain and encodes de se interpretations in terms of "personless sentences". In the previous section, I discussed this idea at the matrix sentence/predicate level. Given that an utterance of any sentence is analyzed as self-ascription of a property, it is easy to adopt the same approach in dealing with attitude reports, to which I now turn. Schlenker does not adopt Lewis's approach to attitude reports partly because there is no way of establishing a clear syntaxsemantics mapping relationship with this proposal. That is, a sentence is traditionally associated with a truth value (extension) or a proposition (intension), and not a property. A property is the intension of a one-place-predicate-like expression (like intransitive verbs, adjectives, and common nouns), not something associated with sentences. However, as shown in the previous section, Japanese utterances often consist of subjectless sentences (or one-place-predicate-like linguistic expressions). This is true of verb complements as well. Consider (19a), which is subject to the semantic rule in (19b) (analogous to 16b) and has the felicity condition given in (19c).

(19) a. [siawase-da]-to dono hito-mo omot-te i-ru.

happy PRES that which person also think-PROG-PRES

'Everyone ${ }_{i}$ thinks that they ${ }_{i}$ are happy.'

b. A sentence of the form [Name $\left.V_{t} V P\right]$ is true at $t_{1}$ in $w_{1}$ iff $\{<x, w, t>\mid$ $<\mathrm{x}, \mathrm{w}, \mathrm{t}>$ is a doxastic alternative of $\llbracket \mathrm{Name} \rrbracket_{\mathrm{c}}$ at $\mathrm{t}_{1}$ in $\left.\mathrm{w}_{1}\right\} \subseteq\{<\mathrm{x}, \mathrm{w}, \mathrm{t}>\mid$ $\left.\| \mathrm{VP} \rrbracket^{\mathrm{g}} \mathrm{c}(\mathrm{x})(\mathrm{w})(\mathrm{t})=1\right\}$

\footnotetext{
${ }^{4}$ See Nakashima and Harada (1995) for a similar attempt within Situation Semantics.
} 
( $\mathrm{P}$ is assumed to a function in $\mathrm{D}_{<\mathrm{e},<\mathrm{s},<\mathrm{t}>>>}$ )

c. An utterance of (19a) by $\alpha$ at $\mathrm{t}_{0}$ in $\mathrm{w}_{0}$ is felicitous iff $\left\{<\mathrm{x}^{\prime}, \mathrm{w}^{\prime}, \mathrm{t}^{\prime}\right\rangle$ $<\mathrm{x}^{\prime}, \mathrm{w}^{\prime}, \mathrm{t}^{\prime}>$ is a doxastic alternative of $\left.\alpha\right\} \subseteq\left\{<\mathrm{x}^{\prime}, \mathrm{w}^{\prime}, \mathrm{t}^{\prime}\right\rangle \mid$ For each person $\mathrm{y},\left\{<\mathrm{x}, \mathrm{w}, \mathrm{t}>\mid<\mathrm{x}, \mathrm{w}, \mathrm{t}>\right.$ is a doxastic alternative of $\mathrm{y}$ at $\mathrm{w}^{\prime}$ in $\left.\mathrm{w}^{\prime}\right\}$ $\subseteq\{<\mathrm{x}, \mathrm{w}, \mathrm{t}>\mid \mathrm{x}$ is happy at $\mathrm{t}$ in $\mathrm{w}\}\}$

In (19a), the embedded clause already denotes a property. So Lewis's idea about de se attitude reports works perfectly here as shown in $(19 \mathrm{~b}, \mathrm{c})$.

When a sentence contains a complete clause as a verb complement as in the Amharic example (20a) (=5a), it is subject to the rule (20b) and receives the interpretation given in (20c).

a. john Jgna naNN yt-lall

John hero I-am says-3rd sg.m

'John says that he is a hero.'

b. A sentence of the form [Name $\left.\mathrm{V}_{\mathrm{t}} \mathrm{S}\right]$ is true at $\mathrm{t}_{1}$ in $\mathrm{w}_{1}$ iff $\{<\mathrm{x}, \mathrm{w}, \mathrm{t}>\mid$ $<\mathrm{x}, \mathrm{w}, \mathrm{t}>$ is a doxastic alternative of $\llbracket$ Name $]^{\mathrm{g}}$ at $\mathrm{t}_{1}$ in $\left.\mathrm{w}_{1}\right\} \subseteq\{<\mathrm{x}, \mathrm{w}, \mathrm{t}>\mid$ $\left.\llbracket \mathrm{S} \rrbracket \mathrm{g}_{\mathrm{c}} \mathrm{x} /<0, \mathrm{e}>(\mathrm{w})(\mathrm{t})=1\right\}$

c. An utterance of (20a)) by $\alpha$ at $\mathrm{t}_{0}$ in $\mathrm{w}_{0}$ is felicitous iff $\left\{<\mathrm{x}^{\prime}, \mathrm{w}^{\prime}, \mathrm{t}^{\prime}\right\rangle$ $<\mathrm{x}^{\prime}, \mathrm{w}^{\prime}, \mathrm{t}^{\prime}>$ is a doxastic alternative of $\left.\alpha\right\} \subseteq\left\{<\mathrm{x}^{\prime}, \mathrm{w}^{\prime}, \mathrm{t}^{\prime}>\mid\{<\mathrm{x}, \mathrm{w}, \mathrm{t}>\mid\right.$ $<\mathrm{x}, \mathrm{w}, \mathrm{t}>$ is a doxastic alternative of John at $\mathrm{t}^{\prime}$ in $\left.\mathrm{w}^{\prime}\right\} \subseteq\{<\mathrm{x}, \mathrm{w}, \mathrm{t}>\mid \mathrm{x}$ is a hero at $\mathrm{t}$ in $\mathrm{w}\}$ \}

Since the Amharic ' $I$ ' is analyzed as a plain variable with a designated index, it is bound by the individual variable binder and the embedded clause is interpreted as the property $\{<\mathrm{x}, \mathrm{w}, \mathrm{t}\rangle \mid \mathrm{x}$ is a hero at $\mathrm{t}$ in $\mathrm{w}\}\}$. Consequently, the 'I' receives a relative interpretation as desired.

The Japanese first person pronouns (e.g., watasi, boku, ore, etc., which all refer to the first person) are only subject to true indexical (i.e., absolute) interpretations. But there are reasons to believe that the so-called reflexive (or logophoric) pronoun zibun is very much like the Amharic ' $\mathrm{I}$ '. It is well know that the Japanese reflexive zibun can be used in a verb complement clause to indicate a de se interpretation as in (21a). In addition, at least in some dialects (including a semi-military dialect) zibun can also behave like a first person pronoun as shown in (21b). This means that these Japanese dialects are virtually equivalent to Amharic regarding the first person "indexical" (assuming that zibun can also be used in a verb complement clause for a de se interpretation in these dialects). Note also that in questions, zibun 'self' is often used to indicate the hearer. (21c) is acceptable in many dialects, including the standard Tokyo dialect. Since a question is a linguistic form that is designed to elicit information about the hearer's attitudes, the fact that zibun can correspond to the hearer in (21c) makes sense. 
a. Dono gakusei-mo [zibun-ga itiban dekiru]-to omot-te i-ru. which student-also [self-NOM most smart-PRES] that think-PROG-PRES 'Every student $t_{i}$ thinks that he $\mathbf{e}_{\mathrm{i}}$ is the smartest.'

b. zibun-wa daizyoobu-de arimasu.

self-TOP fine-be-PRES

'I am doing fine, sir.'

c. Zibun-wa doo-sitai-no?

self-TOP how-do-want-Q

'What do you want to do?'

Although the case of zibun is not completely parallel to the case of Amharic 'I', it provides further evidence for the viewpoint presented in this paper.

Lastly, let me notes that the proposal being defended (which subsumes my earlier proposal in Ogihara 1996) is capable of accounting for the behavior of Japanese tense morphemes in relative clauses as well as in verb complements. Unlike Schlenker's account, my proposal does not rely on the manipulation of contexts to get the right interpretation for "relative indexicals". I also do not depend on the mechanism of feature deletion to obtain relative interpretations of the Amharic 'I', contra von Stechow (2003). Consider (22).

$$
\text { [nanika(-o) saken-de i-ru] otoko-o mi-ta. }
$$

something-ACC shout-PROG-PRES person-ACC see-PAST

'(I) saw a man who was shouting something.'

The relative clause nanika(-o) saken-de i-ru 'who is shouting something' is in the "present tense" but since this is technically analyzed as a tenseless clause, the time of the event is not located at the utterance time. The clause thus denotes the set $\{<\mathrm{x}, \mathrm{t}, \mathrm{w}>\mid \mathrm{x}$ is shouting something at $\mathrm{t}$ in $\mathrm{w}\}$, whereas its modifiee otoko 'man' denotes $\{<\mathrm{x}, \mathrm{t}, \mathrm{w}\rangle \mid \mathrm{x}$ is a man at $\mathrm{t}$ in $\mathrm{w}\}$. These two sets are then intersected to yield the meaning of the object NP as a whole: $\{<\mathrm{x}, \mathrm{t}, \mathrm{W}>\mid \mathrm{x}$ is a man and is shouting something at $t$ in $\mathrm{w}\}$. Since the NP is interpreted in relation to the time of seeing, we obtain the desired simultaneous interpretation. This is the view expressed in Ogihara (1996), and its ability to account for the "simultaneous reading" of relative clauses in the present tense is a clear advantage over its competition. ${ }^{5}$

This proposal accounts for the temporal properties of English infinitival clauses as well. English infinitival clauses can occur as verb complements as in

\footnotetext{
${ }^{5}$ There is a complication that I cannot address in this paper. By adding some appropriate adverbials, (22) could receive another interpretation in which the "present tense" denotes the utterance time. In Ogihara (1996) I suggest that this possibility would be accounted for via the rule of Quantifier Raising. However, as Kusumoto (2005) shows, the QR approach to the ambiguity may be problematic. For the purpose of this article, I simply ignore this problem and concentrate upon the simultaneous reading of the present tense in relative clauses.
} 
(23a) or as a relative clause as in (23b).

(23) a. John claimed to be innocent.

b. I gave John a book for him to read.

Since infinitival clauses are by definition tenseless, it seems straightforward to interpret $(23 a, b)$ as in $(24 a, b)$, respectively.

a. $\{<\mathrm{x}, \mathrm{w}, \mathrm{t}>\mid \mathrm{x}$ is innocent at $\mathrm{t}$ in $\mathrm{w}\}$

b. $\{<\mathrm{x}, \mathrm{w}, \mathrm{t}>\mid$ 'he' reads $\mathrm{x}$ at some time later than $\mathrm{t}$ in $\mathrm{w}\}$

Note that the temporal interpretation specified in $(24 a, b)$ is not linked to the utterance time in any way. Thus in both cases, the time of the infinitival clause is understood to be simultaneous with the time of the matrix clause. The infinitive in (23b) requires a cautionary note since the time of his reading must follow the time of John's giving the book. But this is because of the future-oriented reading associated with the infinitival to read, and the point is simply that this future time is calculated in relation to the matrix event time, not in relation to the utterance time. The data such as $(23 a, b)$ strengthen the argument for my proposal. Since infinitival clauses are tenseless, they contain no temporal indexicals. It seems that the lack of indexicals allows them to receive simultaneous readings in (23a, b). Since Japanese clauses in the "present tense" are also capable of producing the same range of interpretations, I contend that Japanese sentences in the "present tense" are also tenseless.

Regarding the PRO subject in (23a), which only receives a de se reading (Chierchia 1989), we could argue that PRO is in fact not there; the "infinitive clause with a PRO subject" is actually a predicate. This idea would provide us with a desired linguistic expression for obtaining a property and allow us to predict that (23a) must receive a de se interpretation.

Every man claimed to be happy with his job.

Although this analysis might get us into trouble when potential bound variable pronouns occur within the infinitival clause as in (25), I believe this it is an idea worth pursuing. ${ }^{6}$

\section{Conclusion}

In this paper, I have defended the view that the semantics of attitude verbs can be described and explained within Lewis's property-based approach. In so doing, I

\footnotetext{
${ }^{6}$ I thank Uli Sauerland for pointing out some potential problems with this view.
} 
ruled out Schlenker's alternative approach according to which attitude verbs are quantifiers over contexts. My strategy is to look at the whole phenomena of attitude reports from the viewpoint of relative indexical languages. Regarding tense, I assume that Japanese has no indexical tenses, and so-called tensed sentences are actually tenseless. I pursue the same approach with Amharic sentences containing ' $I$ '. The idea is that they are "personless sentences" because the Amharic 'I' is not an indexical. It is a pronoun that must be bound by the individual variable binder. I extend this approach to cases where the linguistic expression being uttered has no overt subject. I believe that my proposal is empirically adequate and intuitively appealing, as far as "relative indexical" phenomena are concerned.

It is clear that this is not the whole picture. Some European languages such as English and German might require morpho-syntactic operations (e.g., feature deletion) to afford the right empirical predictions. For this, we perhaps need a proposal like von Stechow (2003), which for the most part complements what I do in this paper. Despite the limited applicability of the proposal here, I do believe that it is of vital importance to present an analysis of the known data from a new perspective, especially a perspective of a non-European language, and I hope to have accomplished just that.

\section{References}

Austin, J. L.: 1962, How to Do Things with Words, Oxford University Press, Oxford.

Chierchia, Gennaro: 1989, 'Anaphora and Attitudes De Se', in R. Bartsch, J. van Benthem and P. van Emde Boas (eds.) Language in Context, Foris, Dordrecht.

Cresswell, Maxwell J. and Arnim von Stechow: 1982, 'De Re Belief Generalized', Linguistics and Philosophy 5, 503-535.

Frege, Gottlob: 1892, 'Über Sinn und Bedeutung', Zeitschrift für Philosophie und Philosophische Kritik 100: 25-50.

Grice, H.P.: 1975, 'Logic and Conversation' in P. Cole and J. Morgan (eds.) Syntax and Semantics 3, Speech Acts, Academic Press, New York.

Heim, Irene and Angelika Kratzer: 1998, Semantics in Generative Grammar, Blackwell, Oxford.

Hintikka, Jaakko: 1969, 'Semantics for Propositional Attitudes', in J. W. Davis, D.J. Hockney and W. K. Wilson (eds.) Philosophical Logic, D. Reidel, Dordrecht, 21-45.

Kaplan, David: 1977/1989, 'Demonstratives: An Essay on the Semantics, Logic, Metaphysics, and Epistemology of Demonstratives and Other Indexicals' ,in J. Almog, J. Perry, and H. Wettstein (eds.) Themes from Kaplan, Oxford University Press, Oxford, 481-564. 
Kratzer, Angelika: 1998, 'More Structural Analogies between Pronouns and Tenses', in D. Strolovitch and A. Lawson Proceedings of SALT VIII, CLC Publications, Cornell University, Ithaca.

Kusumoto, Kiyomi: 2005, 'On the Quantification over Times in Natural Language', Natural Language Semantics 13, 317-357.

Lewis, David: 1979, 'Attitudes de dicto and de se', The Philosophical Review 88, 513-543.

Montague, Richard: 1973, 'The Proper Treatment of Quantification in Ordinary English', in K.J.J. Hintikka, J. M. E. Moravcsik and P. Suppes (eds.) Approaches to Natural Language, Proceedings of the 1970 Stanford Workshop on Grammar and Semantics, D. Reidel, Dordrecht, 221-242.

Nakashima, Hideyuki and Yasunari Harada: 1995, 'Situated Disambiguation with Properly Specified Representation', in K. van Deemter and S. Peters (eds.) Semantic Ambiguity and Underspecification, CSLI Publications, Stanford, 77-98.

Ogihara, Toshiyuki: 1996, Tense, Attitudes, and Scope, Kluwer Academic Publishers, Dordrecht.

Perry, John: 1977, 'Frege on Demonstratives', Philosophical Review 86, 474-497.

Schlenker, Philippe: 1999, Propositional Attitudes and Indexicality: A CrossCategorial Approach. Doctoral Dissertation, MIT.

Schlenker, Philippe: 2003, 'A Plea for Monsters', Linguistics and Philosophy 26, 29-120.

Stechow, Arnim von: 2003, 'Feature Deletion under Semantic Binding: Tense, Person, and Mood under Verbal Quantifiers', in M. Kadowaki and S. Kawahara (eds.) NELS 33: Proceedings of the Thirty-Third Annual Meeting of the North East Linguistic Society, GLSA, University of Massachusetts, Amherst, 379-404.

Stump, Gregory: 1985, The Semantic Variability of Absolute Constructions, D. Reidel, Dordrecht. 